\title{
Diabetes: a pragmatic therapy with a goal to prevent end stage kidney disease and dialysis
}

\author{
Anil KMandal ${ }^{1,2}$, Nirankar Singh Neki $^{3,4}$ \\ ${ }^{1}$ Consultant in Nephrology Putnam Community Medical Center, Palatka, USA; \\ ${ }^{2}$ Courtesy Clinical Professor of Medicine, University of Florida, Gainesville, USA; \\ ${ }^{3}$ Professor of Medicine Government Medical College, Amritsar, India; \\ ${ }^{4}$ Geriatric Society of India, New Delhi, India. \\ Email: amandal@med-spec.com ; drnsneki123@yahoo.com
}

Received 22 August 2011; revised 24 September 2011; accepted 2 November 2011.

\section{ABSTRACT}

The pragmatic therapy of diabetes which is to achieve satisfactory glycemic control emerges from author's laboratory research. Cell culture studies convincingly demonstrated that high glucose levels above $200 \mathrm{mg} / \mathrm{dL}$ (> $11.1 \mathrm{mmol} / \mathrm{L}$ ) cause damage to vascular endothelial cells. The severity of damage increases with duration of exposure of cultured endothelial cells to high glucose. This glucose-induced endothelial cell damage is mitigated by exposure of the endothelial cells to insulin in the presence of high glucose. There is abundant evidence, including that of author, that insulin treatment prevents diabetes-related microvascular complications including nephropathy and renal failure. Even by taking insulin multiple times, glucose level may reach normal level but only for a short time, because endogenous insulin response is insufficient. Manipulation by oral antidiabetic agents to enhance endogenous insulin release, or increase insulin sensitivity, results in exhaustion of the beta cells, thus changing an easily controllable glycemic state to a pathological uncontrollable glycemic state over the years. Even more troublesome is the lack of established information about the glucose levels that are safe for patients who have diabetes. By the term safe glucose level author means a glucose level which is least toxic to microvascular system and not likely to cause neuropathy, foot ulcer, gangrene, sexual dysfunction, and kidney failure. To achieve that glucose control is a formidable task for the patients as well as the doctors and nurses. Nevertheless, persistence is essential in diabetes management. Thus, on one hand patients must be astute in their care and doctors and nurses must be diligent in implementing and maintaining optimal glucose control in their patients. Both parties must be cohesive to achieve only one goal, which is to keep patients learn to cope with diabetes and thrive. Randomized clinical trials of glycemic control comparing one insulin against another, or insulin against oral hypoglycemic agents is not ethical. Such clinical trials will shed no light in improving diabetes care. On the other hand, it may prove to be detrimental.

Keywords: Diabetes; Paradigm Of Therapy; Postprandial Hyperglycemia; Endothelial Cell Injury; Insulin Treatment; Lantus Insulin; Regular Insulin

\section{RATIONALE OF INTENSIVE INSULIN THERAPY: A MECHANISM OF CELLULAR INJURY CAUSED BY HYPERGLYCEMIA}

Glucose levels in a subject who is not diabetic are:

- After overnight fasting less than $126 \mathrm{mg} / \mathrm{dL}(7 \mathrm{mmol} /$ $\mathrm{L})$, better is less than $100 \mathrm{mg} / \mathrm{dL}(5.5 \mathrm{mmol} / \mathrm{L})$

- 2 hours after an unrestricted breakfast or lunch (not tea and toast or salad and soup) less than 200 $\mathrm{mg} / \mathrm{dL}(<11.1 \mathrm{mmol} / \mathrm{L})$; better is less than $140 \mathrm{mg} / \mathrm{dL}$ $(<7.7 \mathrm{mmol} / \mathrm{L})$.

On the other hand, in subjects with established diabetes but untreated: overnight, fasting glucose can be over $200 \mathrm{mg} / \mathrm{dL}(>11 \mathrm{mmol} / \mathrm{L})$ and 2 hours after breakfast or lunch can go as high as 400 or $500 \mathrm{mg} / \mathrm{dL}$ (22.2 - 27.7 $\mathrm{mmol} / \mathrm{L}$ ). The classification of Type 1 and Type 2 diabetes is not used because the classification sheds no light in glycemic control or prevention strategy.

People with established diabetes whose blood glucose level remain elevated above $200 \mathrm{mg} / \mathrm{dL}(>11.1 \mathrm{mmol} / \mathrm{L})$ without treatment with insulin can develop complications acutely, or in a protracted (chronic) fashion. While acute complications reverse with intensive therapy, chronic complications do not necessarily reverse even with intensive therapy. 
The two serious acute complications are diabetic ketoacidosis and diabetic coma. High uncontrolled sugar level is associated with frequent urination accompanied by excessive loss of body water (dehydration). Lack of insulin, which results in very high blood sugar level even up to $1000-1500 \mathrm{mg} / \mathrm{dL}(55.5-83.3 \mathrm{mmol} / \mathrm{L})$, is associated with elevated levels of growth hormone, adrenaline, and cortisol. All these secondary hormones lead to breakdown of fat and increased release of fatty acids from liver. The byproducts of these fatty acids are acetoacetic acid, which lower blood $\mathrm{pH}$ and make the person acidotic. As a result of dehydration, kidney function is decreased giving rise to acute kidney failure.

Further, very high blood glucose levels for instance, $800 \mathrm{mg} / \mathrm{dL}$ (44.4 mmol/L) or $1000 \mathrm{mg} / \mathrm{dL}$ (55.5 mmol/L) increase the osmotic pressure in the blood and produce an imbalanced state of the water content between intracellular space and extracellular space, which is the circulating blood space. Intracellular fluid spaces are brain, liver, heart, and kidney. When the osmotic force in the circulating system increases, water moves away from the above organs into the circulating system to make the balance of the water content between the two spaces. The result is drying of the cells. When brain cells dry up, brain shrinks and herniates, resulting in coma. Liver cells become dry and lead to necrosis with elevated liver enzymes; similarly, heart cells undergo necrosis and lead to heart failure, and kidney cells necrosis leads to acute kidney failure. Therefore, a diabetic patient with very high glucose levels, if not treated quickly with insulin infusion and fluid therapy, can develop catatrophic events associated with high mortality.

\section{CHRONIC COMPLICATIONS DUE TO UNTREATED HIGH GLUCOSE LEVELS IN THE BLOOD NOT HIGH ENOUGH TO CAUSE ACUTE COMPLICATIONS AS STATED ABOVE BUT CAN CAUSE ONE OR MORE OF THE FOLLOWING COMPLICATIONS}

These complications are not in any particular order:

- Retinopathy leading to partial or complete blindness

- Nephropathy leading to end stage renal failure and dialysis

- Neuropathy leading to foot ulcer

- Sexual dysfunction

- Gangrene of foot or toes leading to amputation

- Coronary heart disease leading to myocardial infarction or heart attack

- Neurogenic bladder leading to recurrent urinary retention and urinary tract infection

- Gastroparesis and paralytic ileus leading to recurrent vomiting, loss of nutrition, and cachexia.
When patients present to a doctor's office with one complication, such as foot ulcer or gangrene, they usually have one or more of the other complications. These complications are due to microvascular and macro-vascular lesions. An important question is about the threshold of glucose level above which complications are likely to develop and below which complications are unlikely to develop. Even more important question is why don't glucose particles in the normal range $(80-100 \mathrm{mg} / \mathrm{dL}$ or 4.4 - $5.5 \mathrm{mmol} / \mathrm{L}$ ) produce any complications but do so when they increase to $200 \mathrm{mg} / \mathrm{dL}$ (11 mmol/L) or more. What difference does it make for increase in range of the same glucose particles? Therefore, a big question is: are glucose particles same or different in someone who is not diabetic versus who is diabetic?

Author's research involving cell culture studies attests to the fact that elevated glucose level, in and of itself, even of similar particles, has something to do with the complications. In the laboratories of the author, porcine vascular endothelial cells were cultured for growth of the cells and then treated with normal concentration of glucose $(90 \mathrm{mg} / \mathrm{dL}$ or $5 \mathrm{mmol} / \mathrm{L})$ or high concentration of glucose $(540 \mathrm{mg} / \mathrm{dL}$ or $30 \mathrm{mmol} / \mathrm{L})$ for a period of 2 days, 6 days, or 10 days. Additional cultured cells were treated with glucose of the same concentrations as above and insulin or with glucose, insulin, and heparin.

Why are vascular endothelial cells chosen and not other cell types? There is good evidence in the literature that vascular endothelial cells are most vulnerable to injury by high blood glucose levels (hyperglycemia). High glucose levels bathe all the cells in the body. But why does damage occur in some cell types in diabetes? The answer is that most cells are able to reduce the transport of glucose inside the cells when they are exposed to high glucose levels, so that their internal glucose concentration remains constant. In contrast, the cells damaged by high glucose concentration are those that cannot retard transport of glucose inside the cells. Thus, in diabetes, endothelial cells and mesangial cells cannot reduce transport of glucose inside the cells in the state of high glucose levels in the blood. In essence, defect in membrane transport of endothelial cells permits excessive amount of glucose to enter inside the cells when glucose level is high. Therefore, complications that develop in diabetes must involve mechanisms of excessive amount of glucose inside the cells, rather than outside of the endothelial cells [1].

In our cell culture studies, we have demonstrated crystalline structures that are presumably glucose in severely damaged cells, as shown in Figures 1(a) and 1(b).

Many hypotheses or pathways were proposed to explain high glucose-induced cellular damage that is set in and perpetuates damage to the various organs and gives rise to appearance of clinically evident disease, such as 


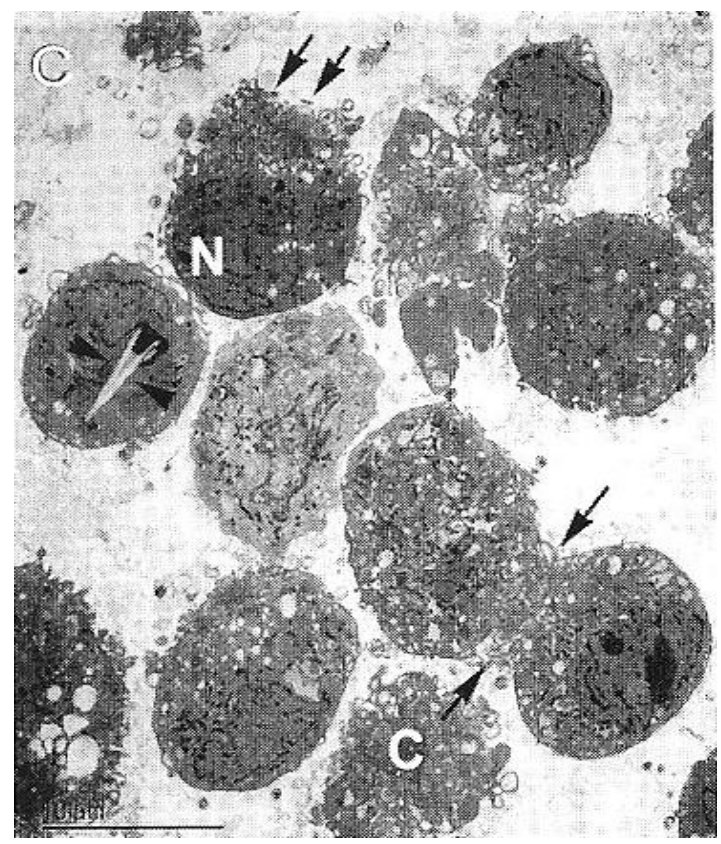

(a)

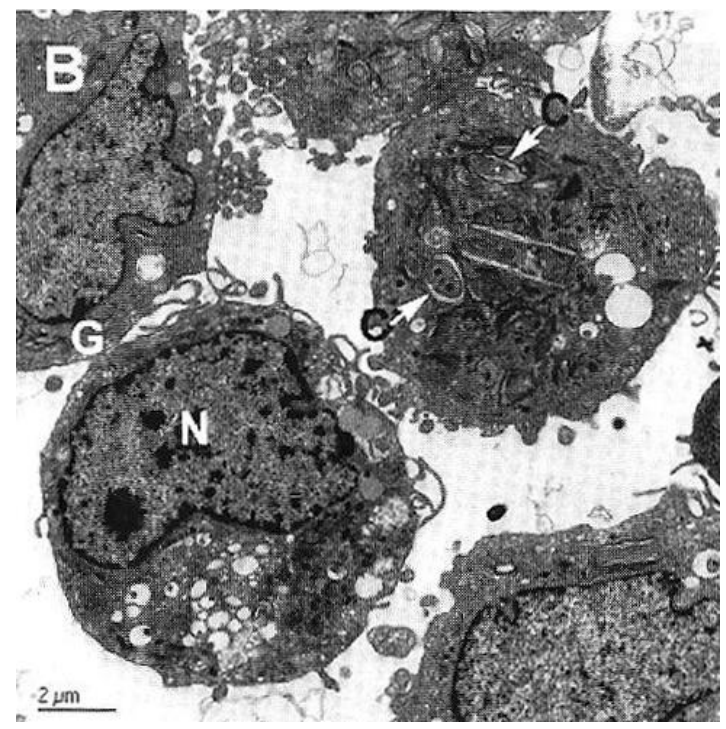

(c)

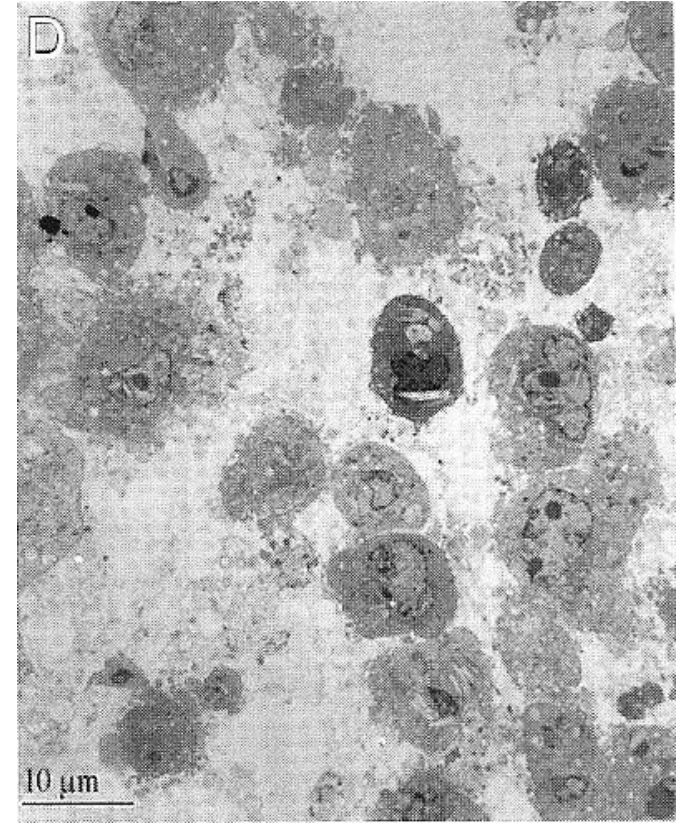

(b)

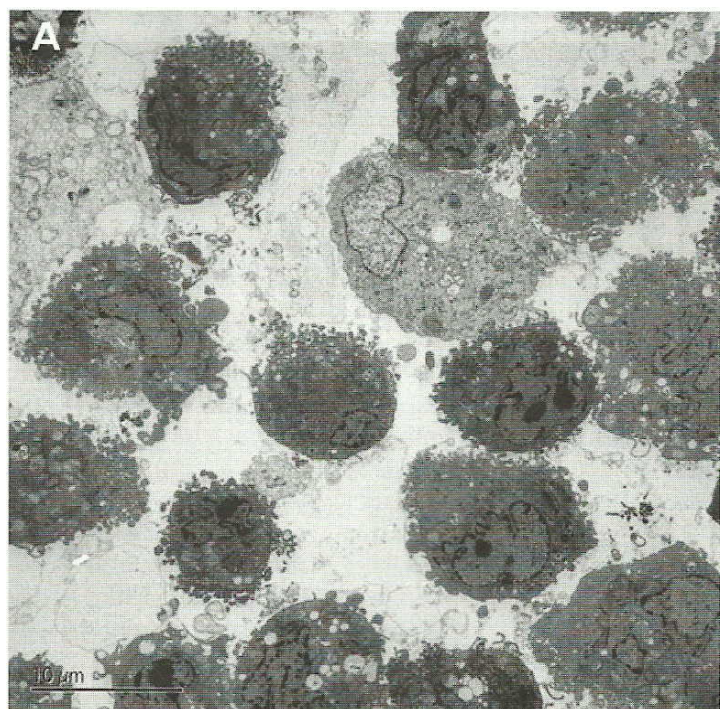

(d)

1(a): $\mathrm{C}=$ connection between damaged cells between arrows; $\mathrm{N}=$ damaged nucleus; Crystalline structures between dark arrow heads; 1 (b): Note crystalline structure in an isolated cell in the open area; $1(\mathbf{c}): \mathrm{N}=$ normal nucleus; Crystalline structures between white arrows.

Figures 1(a), 1(b), 1(c) and 1(d) adapted from Mandal, etal. Electron microscopic analysis of glucose-Induced endothelial damage in primary culture (2006).

retinopathy, heart attack, foot ulcer, gangrene, or kidney failure. None of the pathways thus far advanced explain damage to all the organs in a unified fashion. Author has proposed a better unified theory, which is ischemia (markedly reduced blood flow), which explains damage to all the organs. Reduced blood flow in an indolent fashion does not cause necrosis but causes atrophy. This is evident in heart as myocardial fibrosis and cardiomyopathy or atrophic tubules and interstitial fibrosis in kid- neys. Progressive kidney failure is more due to loss of tubules and interstitial fibrosis rather than glomerular sclerosis. Inability to achieve penile erection is clearly due to lack of blood flow through the penile microvasculature. Reduced blood flow can be associated with increased vascular permeability, resulting in exudation of plasma proteins in the free surface outside of the vessels. This is best seen as hemorrhages and exudates in the retina of eyes and as protein leak from kidney glomeruli in 
diabetes. Reduction of high blood glucose to normal or near normal level with insulin results in mitigation of endothelial damage and repair; and consequently, partial or complete recovery of organ function. Like this author, other authors have considered that diabetes-specific microvascular disease in the eyes (retina), kidney glomeruli, and vasa nervorum (small vessels surrounding nerves in feet and penis) has similar pathophysiologic features [1].

Fundamentally, the worst effects of high glucose level will be felt uniformly in all organs as considered by this author, and other authors [1]. Once again, the uniformly worse effect of high blood glucose is necrosis of vascular endothelial cells, sloughing off of these cells into the capillary lumina forming microthrombi along with cholesterol and platelet deposits and resulting in occlusion of capillaries with slight or no blood flow to the organs. Hyperglycemia (high glucose level) was induced in rats to find changes in kidney glomeruli in the past. Very subtle changes were found in the kidney glomeruli; no changes were found in the tubules and interstitium. Rats did not develop kidney failure. This is the worst pitfall of the utility of experimental studies in live animals in trying to elucidate the pathogenesis of the complications associated with diabetes in humans. On the other hand, cell culture experiments done by the author and the collaborating authors have paved the way in better understanding of the pathogenesis of diabetic complications and how will these complications be adequately prevented.

The exact mechanisms of injury to the vascular endothelial cells and tubular epithelial cells caused by high glucose levels are not yet fully elucidated. Some authors have shown that high blood glucose levels increase oxidative stress and increase the production of reactive oxygen species [2].

We have considered that toxic oxygen radicals may be involved in ischemic injury to the organs. Thus we designed an experiment to determine that. Glutathione is an important enzyme for oxidative stress. Therefore, by inhibiting glutathione, oxidative injury may increase. We treated vascular endothelial cells with a potent glutathione inhibitor, buthionine sufoximine for 2 days and 6 days. After 6 days of treatment, endothelial cells had undergone severe necrosis beyond recognition. Thus, this experiment suggests that deficiency of glutathione may be an important mechanism of diabetic microvascular complications [3].

Our cell culture studies have helped us to undermine the mechanism of protection against high glucose-induced cellular damage. We treated the cultured endothelial cells with insulin and with insulin and heparin in the presence of high glucose level in the culture medium. We noted slight or no morphological damage to cells. This is shown in Figures 1(c) and 1(d). We have postu- lated that insulin reduces oxidative stress. Heparin seems to be additive to insulin in that effect. This had been shown by my collaborating author [4].

There is one mechanism by which heaprin may synergize insulin. We have found that high glucose as well as insulin increases endothelin-1 production in the cultured endothelial cells. Heparin is a potent inhibitor of endothelin-1 [5]. Endothelin-1 is a potent vasoconstrictor and can aggravate ischemic injury to the endothelial cells. Therefore, by inhibiting endothelin-1 production, heaprin may synergize insulin effect in protection against high glucose-induced cellular injury [6].

Since persistent hyperglycemia is the determinant of diabetic complications, lowering of high glucose level by insulin therapy is the logical answer for prevention of its complications.

High blood glucose level can be lowered by oral antidiabetic agents, insulin injections, or a combination of both. It is evident in the literature that lowering of high blood glucose level with intensive insulin therapy can prevent diabetic complications [7-10], but no systematic studies were done to unequivocally show that simply by lowering of high glucose level with oral antidiabetic agents, such as glyburide, metformin, or Januvia will prevent diabetic complications. Occasional studies showed that use of metformin alone in Type 2 diabetes reduced the risk of death from myocardial infarction. The most important caveat of Type 2 diabetes is that some of the patients in this type of trial may not have diabetes. Type 2 diabetes was never defined appropriately, such as by 2 $\mathrm{h}$ postprandial glucose level or glucose tolerance test. Diabetes whose 2-h postprandial glucose is above 200 $\mathrm{mg} / \mathrm{dL}(>11.1 \mathrm{mmol} / \mathrm{L})$, oral antidiabetic agents can be used in addition to insulin to achieve better glucose control than either alone. However, the primary outcomes, such as microvascular complications, are not affected, despite improved glucose control as shown by this study.

390 patients treated with insulin in the outpatient clinics of three hospitals for a period of 4.3 years received metformin $(850 \mathrm{mg})$ or placebo ( $1-3$ times daily). The primary end point was an aggregate of microvascular and macrovascular morbidity and mortality, as separate aggregate scores. Metformin treatment prevented weight gain, improved glycemic control, and reduced insulin requirement but didn't improve the primary end points. [11].

In author's cell culture studies, when cells were treated with glucose and insulin, glucose measurement in culture plate showed slight or no change in concentration of glucose, although morphologically cells were found to be intact. This finding suggests that insulin has a vascular protective effect, which may be independent of simply lowering of glucose [3]. Thus, combining clinical studies with the adjunct of cell culture studies, it is 
prudent to state that insulin is the cornerstone of therapy for prevention of cellular damage and hence appearance of clinical complications.

\section{PREVENTION OF CELLULAR IN- JURY AND PROTECTION AGAINST CLINICAL COMPLICATIONS}

By now the readers have developed a grasp of the fundamentals of diabetes mellitus (DM) and how much damage high glucose causes to the various organs. Now is the time for the readers to know what we can do to bring down the glucose level and keep that to near normal level, so that anatomical and functional damage to the various organs can be abated. But there is no evidence that keeping the sugar level to normal level will completely prevent the damage (injury) or repair any damage that has already incurred. Keeping a normal glucose level with therapy is not easy to accomplish. Lowering glucose level to near normal level is rather a reality. Further, risk of hypoglycemic reactions is quite high when one attempts to lower the glucose to normal levels. Therefore, a reasonable approach will be to reach a satisfactory glycemic control $(<200 \mathrm{mg} / \mathrm{dL})$ [10] in our diabetic patients, whereby the organ damage may be halted or repaired and hypoglycemic reactions can be avoided. While no information is available with regard to ideal glucose level in a diabetic patients, when complications can be reduced there is a subtle evidence that keeping 2-hour postprandial glucose level to less than $200 \mathrm{mg} / \mathrm{dL}(<11.1$ $\mathrm{mmol} / \mathrm{L})$ is beneficial $[10,12]$.

\subsection{Control of Hyperglycemia and Monitoring of the Control}

Utmost attention should be focused to identify and treat DM at the early stage when no complication has surfaced. Aggressive control of hyperglycemia with intensive insulin therapy when complications have already developed, such as; renal failure increases the risk of ireversible hypoglycemia and high mortality. A combination of long-acting and short-acting insulin is the cornerstone of therapy for control of hyperglycemia when blood glucose level is consistently above $200 \mathrm{mg} / \mathrm{dL}(>11.1$ $\mathrm{mmol} / \mathrm{L})$. Complications, as already stated, are unlikely to develop or, if they exist, are less likely to progress, if the blood glucose level is kept consistently below 200 $\mathrm{mg} / \mathrm{dL}(<11.1 \mathrm{mmol} / \mathrm{L})$. On the contrary, slight or no information is available with regard to effectiveness of oral hypoglycemic agents alone in affording control of postprandial hyperglycemia and in preventing microvascular complications.

\subsection{Technical Pitfalls in Control of Hyperglycemia}

Most patients check their blood glucose before breakfast and before dinner neither of which provides good information of glycemic control. Literature information on 2 hour postprandial blood glucose testing is also scarce. Few studies have compared the validity of the glucose levels between two-time periods (fasting and 2 hours after a meal) in relation to microvascular or macrovascular complications. HbAlc is most commonly used to determine glycemic control. However, HbA1c levels are not always parallel with individual glucose levels [13]. Our data show a poor correlation between $\mathrm{HbA} 1 \mathrm{c}$ or fasting glucose, and renal function parameters [14].

\subsection{Compliance}

A recent report indicates that only 17 percent of Type 2 diabetes patients take insulin. Another 17 percent of Type 2 diabetes patients take a combination of insulin and oral agents, whereas 54 percent are treated with only oral agents [15]. Despite extensive efforts and more oral drugs available, attempts at reaching and maintaining nearnormal glycemic levels in actual clinical practice have been largely unsuccessful. The failures are mainly due to lack of diet control and irregularities in taking prescribed doses of insulin. The most difficult part of satisfactory glucose control is refusal of most patients to adhere to a strict diet regimen [15]. Patients are not able to accept or cope with the life style changes required in diabetes. In underdeveloped countries, social stigma is even worse making patients feel embarrassed to go to doctors, thus delaying treatment. Similarly, regular sugar testing, special diet preparation, and long-term treatment program prove to be expensive to many individuals in underdeveloped and developing countries. Controlled diet therapy is difficult in environment of multiple families living together in those countries. Personal or family income is often meager to buy required amount of insulin and diabetes supplies. Worst of all is lack of a refrigerator in many households. Thus, insulin kept in room temperature, which may be $90^{\circ}-100^{\circ} \mathrm{F}$ or more can cause loss of its potency and effectiveness to reduce blood sugar.

\subsection{Fallacy in Classification}

The worst fallacy in current diabetes care is to ascribe every adult with hyperglycemia automatically as Type 2 diabetes and hence prescribe oral antidiabetic agents and a renin-angiotensin inhibitor drug. Author recommends using the term "established diabetes"-not Type 1 or Type 2 diabetes - when random blood glucose or 2-hour postprandial glucose is $>200 \mathrm{mg} / \mathrm{dL}(>11.1 \mathrm{mmol} / \mathrm{L})$.

\subsection{Therapy for Diabetes}

The most important therapy for diabetes is obviously replacement therapy, which is insulin. Satisfactory control of blood glucose levels $(<200 \mathrm{mg} / \mathrm{dL}$ or $<11.1 \mathrm{mmol} / \mathrm{L})$ 
is the key to prevention of the microvascular and possibly macrovascular complications of diabetes and is more effectively accomplished with insulin than with oral drugs. Early insulin therapy with resultant satisfactory glucose control appears to spare or delay beta-cell damage and might even restore beta-cell function. Glucose control can be graded into three categories, according to this study, as shown below [10].

\section{2-hour postprandial Glucose Levels}

Satisfactory $=<200 \mathrm{mg} / \mathrm{dL} \quad(<11.1 \mathrm{mmol} / \mathrm{L})$

Fair $\quad=200-300 \mathrm{mg} / \mathrm{dL}(11.1-16.6 \mathrm{mmol} / \mathrm{L})$

Poor $\quad=>300 \mathrm{mg} / \mathrm{dL} \quad(>16.6 \mathrm{mmol} / \mathrm{L})$

Beta-cell function tends to decline over time in patients with Type 2 diabetes as insulin resistance leads to beta-cell exhaustion, and elevated lipids and glucose that exert toxic effects on beta cells [15].

The following approaches will permit accomplishing the most important goal of prevention of endothelial cell injury, and thereby mitigating surfacing of diabetic complications:

- Satisfactory glucose control.

- Frequent office visits to maintain glucose and blood pressure controls.

\section{SATISFACTORY GLUCOSE CONTROL: INSULIN THERAPY}

The author concurs with the approaches by Dr. Palumbo to achieve treatment goals for diabetes [15]. For patients with glucose levels lower than $200 \mathrm{mg} / \mathrm{dL}$ at diagnosis, the authors' recommendation is diet control, avoid excesses (buffet lunch or dinner, parties), and regular exercise with a goal to reduce weight for those who are overweight. Author does not recommend oral agent(s), because oral agents lower fasting glucose and HbAlc but not $2 \mathrm{~h}$ PP glucose level, as shown in this patient (Table 1). Table 1 shows that the fasting glucose but not $2 \mathrm{hPP}$ glucose is decreased with metformin. HbAlc remains elevated. Discontinuation of metformin and initiation of insulin glargine resulted in control of fasting and $2 \mathrm{hPP}$ glucose levels and improvement in renal function. $\mathrm{Hb}$ Alc is also reduced.

For those with random (post-meal) glucose above 200 $\mathrm{mg} / \mathrm{dL}$ or with $2 \mathrm{hPP}$ glucose levels above $200 \mathrm{mg} / \mathrm{dL}$ ( $>$ $11.1 \mathrm{mmol} / \mathrm{L}$ ), insulin is the cornerstone of therapy. Our experimental studies reinforce the clinical studies in that insulin therapy reverses toxic effects of high glucose on endothelial cells thereby preventing complications $[3,6]$.

This is in agreement with a previous report. A ten year follow up of intensive glucose control in Type 2 diabetes indicates that intensive glucose control starting at the time of diagnosis is associated with a significantly decreased risk of myocardial infarction and death from any cause, in addition to the well-established reduction in the risk of microvascular disease. That study highlights the
Table 1. Paradigm of therapy by mandal diabetes research foundation. 54y Cambodian female: long history of diabetes medication: Metformin $1000 \mathrm{mg} \times 2$ daily.

\begin{tabular}{|c|c|c|c|c|c|}
\hline \multicolumn{6}{|c|}{ October 2010} \\
\hline & $\begin{array}{l}\text { Glucose } \\
\text { mg/dL }\end{array}$ & $\begin{array}{c}\text { BUN } \\
\mathbf{m g} / \mathbf{d L}\end{array}$ & $\begin{array}{c}\text { Scr } \\
\mathbf{m g} / \mathbf{d L}\end{array}$ & $\begin{array}{c}\text { eGFR } \\
\text { ml/min }\end{array}$ & $\begin{array}{c}\text { HbA1c } \\
\%\end{array}$ \\
\hline Fasting & 132 & 17 & 0.61 & 103 & 10.4 \\
\hline $2 \mathrm{hPP}$ & 292 & & & & \\
\hline \multicolumn{6}{|c|}{$\begin{array}{l}\text { Metformin discontinued } \sim \text { Glargine insulin } 25 \text { units subcutane- } \\
\text { ously each after breakfast and dinner prescribed }\end{array}$} \\
\hline \multicolumn{6}{|c|}{ February 2011} \\
\hline & $\begin{array}{l}\text { Glucose } \\
\text { mg/dL }\end{array}$ & $\begin{array}{l}\text { BUN } \\
\mathbf{m g} / \mathbf{d L}\end{array}$ & $\begin{array}{c}\text { Scr } \\
\mathbf{m g} / \mathbf{d L}\end{array}$ & $\begin{array}{c}\text { eGFR } \\
\mathrm{ml} / \mathbf{m i n}\end{array}$ & $\underset{\%}{\text { HbA1c }}$ \\
\hline Fasting & 113 & 21 & 0.56 & 113 & 7.9 \\
\hline $2 \mathbf{h P P}$ & 204 & 19 & 0.60 & 104 & \\
\hline
\end{tabular}

$\mathrm{Scr}=$ serum creatinine; eGFR = estimated glomerular filtration rate.

importance of glucose-lowering in reducing the risk of coronary events and death from any cause. These findings strengthen the rationale for attaining optimal glycemic control and indicate emergent long-term benefits on cardiovascular risk [16].

\section{PRINCIPLES OF INSULIN THERAPY}

A variety of insulin preparations are available in the market: short-acting, intermediate-acting, and long-acting. Author recommends sugar testing 2-h after each meal, bed time, and upon waking in middle of night for satisfactory glucose control. It is recommended that insulin therapy begin with long-acting insulin. There are two types of long-acting insulin available in the market.

\subsection{Insulin Glargine (Lantus $\left.{ }^{\circledR}\right)$}

A recombinant DNA analog of human insulin, forms microprecipates in subcutaneous tissue, delaying its absorption and prolonging its duration of action. Unlike NPH, lente, or ultralente (out of market in the USA), Lantus has no peak concentration, thus mimicking continuous infusion of rapid-acting regular insulin from a subcutaneous pump.

\subsection{Insulin Detemir (Levemir $\left.{ }^{\circledR}\right)$}

According to pharmaceutical companies, both lantus insulin and insulin detemir have similar onset of action in about 4 hours and reaches its peak in 8 to 9 hours. Effect decreases after 12 hours. Which one of the long-acting insulins lantus or detemir to choose? Author prefers lantus, because he has more experience with that product. There are no data to support or refute that long-acting insulin, such as Lantus or Levemir will be effective for 24 hours in those with normal kidney function. Why normal kidney function? Because insulin is excreted by the kid- 
neys, thus in diabetes patients with decreased kidney function, insulin excretion will be reduced in proportion to decrease of kidney function. Thus, insulin dosage will be reduced proportionately and will be given at longer intervals such as once a day. Frequent dosing of insulin in patients with decreased kidney function may cause irreversible hypoglycemia and a vegetative life.It is important for the readers to know that Lantus or Levemir taken twice daily after breakfast and dinner (12 hours apart) has made a big difference in attaining satisfactory glucose control among author's patients in the office and in the hospital. Here is one such example.

A 56 years white female was seen in consultation in February of 2010 , for acute elevation of blood glucose and renal insufficiency. On history taking and physical examination, her main problem is bilateral foot ulcer under the heel: one is necrotic looking, and the other not so bad looking. She had already right great toe amputated. She gives history of diabetes for 26 years. She has had no other complaint. She was taking Lantus insulin once a day and regular insulin on a sliding scale. She had persistently poor glucose control. Following are some of the records.

$\begin{array}{ccc}\text { February } 2010 & 366 \mathrm{mg} / \mathrm{dL} & (20.3 \mathrm{mmol} / \mathrm{L}) \\ \text { September 2009 } & 517 \mathrm{mg} / \mathrm{dL} & (28.7 \mathrm{mmol} / \mathrm{L}) \\ & 489 \mathrm{mg} / \mathrm{dL} & (27.1 \mathrm{mmol} / \mathrm{L}) \\ \text { November 5 2006 } & 442 \mathrm{mg} / \mathrm{dL} & (24.5 \mathrm{mmol} / \mathrm{L}) \\ \text { November 4 2006 } & 518 \mathrm{mg} / \mathrm{dL} & (28.7 \mathrm{mmol} / \mathrm{L}) \\ \text { January 2006 } & 500 \mathrm{mg} / \mathrm{dL} & (27.7 \mathrm{mmol} / \mathrm{l})\end{array}$

In the hospital, she was started on Lantus insulin after breakfast and after dinner (12 hours apart) and aspart insulin on a sliding scale which she followed after discharge. She was discharged in February of 2010. She recorded her sugar one hour after breakfast, lunch, and dinner after discharge from the hospital. Only three levels were over $200 \mathrm{mg} / \mathrm{dL}$ after breakfast and one each after lunch and dinner from March 5-25, 2010. In a total of 60 readings (Table 2), only one level was $300 \mathrm{mg} / \mathrm{dL}$ (16.6 $\mathrm{mmol} / \mathrm{L})$. She takes Lantus insulin 20 units after breakfast and 20 units after dinner and aspart insulin on a sliding scale. Finally, this patient exemplifies that foot ulcer, gangrene; amputation and rapidly deteriorating kidney function are the ultimatum of uncontrolled glucose level in the range of $300-500 \mathrm{mg} / \mathrm{dL}$ or higher.

Another patient is presented here to demonstrate improved well-being and improved or stable renal function with author's paradigm of therapy. A 77 year white female was first seen by the author in July of 2010 for control of diabetes and renal function with the author's paradigm of therapy. She gave a history of diabetes for 12 - 13 years and loss of sensation in the feet suggesting diabetic neuropathy. She was admitted to a local hospital
Table 2. Finger stick glucose levels (mg/dL).

\begin{tabular}{cccc}
\hline March 2010 & Breakfast & Lunch & Dinner \\
\hline $\mathbf{5}$ & 96 & 151 & 143 \\
$\mathbf{6}$ & 123 & 115 & 136 \\
$\mathbf{7}$ & 150 & 165 & 146 \\
$\mathbf{8}$ & 161 & 110 & 144 \\
$\mathbf{9}$ & 88 & 160 & 238 \\
$\mathbf{1 0}$ & 109 & 75 & 128 \\
$\mathbf{1 1}$ & 300 & 130 & 109 \\
$\mathbf{1 2}$ & 151 & 129 & 110 \\
$\mathbf{1 3}$ & 120 & 111 & 89 \\
$\mathbf{1 4}$ & 139 & 191 & 125 \\
$\mathbf{1 5}$ & 155 & 173 & 98 \\
$\mathbf{1 6}$ & 205 & 181 & 103 \\
$\mathbf{1 7}$ & 48 & 75 & 120 \\
$\mathbf{1 8}$ & 111 & 162 & 113 \\
$\mathbf{1 9}$ & 71 & 225 & 151 \\
$\mathbf{2 0}$ & 265 & 112 & 170 \\
$\mathbf{2 1}$ & 61 & 105 & 182 \\
$\mathbf{2 2}$ & 85 & 160 & 93 \\
$\mathbf{2 3}$ & 52 & 152 & 65 \\
$\mathbf{2 4}$ & 146 & 104 & 182 \\
$\mathbf{2 5}$ & 86 & & \\
\hline
\end{tabular}

in January of 2010 for right foot ulcer and received regular insulin only during the hospital stay. She did not receive insulin before or after hospital discharge. Medication at the time of her office visit with the author included:

Furosemide $40 \mathrm{mg}$ orally daily

Gemfibrozil (Lopid ®) $600 \mathrm{mg}$ orally twice daily

Amlodipine $5 \mathrm{mg}$ orally once daily

Glyburide $5 \mathrm{mg}$ orally twice daily

Aranesp $60 \mathrm{mcg}$ injection every 2 weeks

Acarbose $50 \mathrm{mg}$ orally twice daily

Hydrochlorothiazide (HCTZ) $25 \mathrm{mg}$ orally daily

Atacand (angiotensin receptor blocker) was discontinued 6 months prior to office visit.

During this office visit, furosemide was discontinued, HCTZ was reduced to $12.5 \mathrm{mg}$ orally daily, and amlodipine was increased to $5 \mathrm{mg}$ orally twice daily for blood pressure control. Basic metabolic panel: Fasting and 2hour postprandial and $\mathrm{HbA} 1 \mathrm{c}$ were ordered. In early August of 2010 patient returned to office. She did her laboratory prior to office visit, in late July.She was started on 1) Lantus insulin, 25 units subcutaneously after breakfast and 25 units after dinner (12 hours apart), 2) Regular insulin (Novolin $\left.{ }^{\circledR}\right) 5$ units subcutaneously with breakfast, lunch and dinner, 3) Check finger-stick glucose 2 hours after each meal and at bedtime, taking additional regular insulin on a sliding scale, 4) Patient is already following an 1800 calorie American Diabetes Association diet, 5) She continues acarbose $50 \mathrm{mg}$ twice daily with meals. 


$\begin{array}{ccc}\text { July 2010 } & \text { Fasting } & \text { 2hPP } \\ \text { Glucose (mg/dL) } & 299 & 482 \\ \text { BUN (mg/dL) } & 37 & 35 \\ \text { Serum creatinine (mg/dL) } & 1.43 & 1.60 \\ \text { eGFR (ml/min) } & 38 & 33 \\ \mathrm{Na}(\mathrm{mmol} / \mathrm{L}) & 140 & 137 \\ \mathrm{~K}(\mathrm{mmol} / \mathrm{L}) & 4.2 & 4.5 \\ \mathrm{HbA} \mathrm{c}(\%) & 11.3 & \\ \text { Average glucose (mg/dL) } & 278 \\ \text { Hemoglobin }(\mathrm{g} / \mathrm{dL}) & 13.5 & \\ \text { Hematocrit }(\%) & 40.7 & \end{array}$

She obtained laboratory as before and returned in 5 weeks. Her fasting glucose decreased to $173 \mathrm{mg} / \mathrm{dL}(9.6$ $\mathrm{mmol} / \mathrm{L}$ ), and hemoglobin A1c decreased to $9.3 \%$. Renal function remained unchanged. Lantus insulin was increased to 30 units after breakfast and 30 units after dinner. In October of 2010, her $2 \mathrm{hPP}$ was $174 \mathrm{mg} / \mathrm{dL}$, HbAlc $8.2 \%$, Serum creatinine decreased to $1.54 \mathrm{mg} / \mathrm{dL}$, and eGFR increased to $35 \mathrm{ml} / \mathrm{min}$. Lantus insulin further increased to 35 units after breakfast and dinner which she is taking now. The current laboratory data are shown at the bottom of the page:Her 24 hour urinary protein was $398 \mathrm{mg}$ and creatinine clearance was $47.5 \mathrm{ml} / \mathrm{min}$. Her glucose control is much improved and kidney function is stable. While kidney function could be better if the patient stops taking furosemide, but she feels the need to take the furosemide. She has insignificant proteinuria. She lives a good life.

\subsection{Short-Acting Insulins Are}

a. Insulin aspart (Novolog®)

b. Lispro (Humalog®)

c. Humulin ${ }^{\circledR}$

d. Novolin $\AA$

While aspart or lispro are very rapid acting (action starts within 20 minutes), Humulin R or Novolin R, are fast and action starts within 30 - 40 minutes. Intermediate-acting insulins are NPH (Neutral Protamine Hagedorn), Humulin N, and Novolin N. Then there are 70/30 mixed insulins. These 70/30 insulins are mixture of long acting and short acting insulins. 70/30 insulin is turbid, and generally not effective. Insulin must be clear to be effective.

\subsection{Insulin Regimen as Proposed by the Author}

Regimen 1. All diabetic patients, when they are first seen in author's office, can be divided into following groups. Group 1: Not on insulin but taking multiple oral antidiabetic agents. These are glyburide, metformin, Januvia $\AA$, glimepiride. Group 2: As above plus a small dose of regular or Lantus insulin at bedtime. Group 3: Lantus 1015 after breakfast or at bedtime. No coverage throughhout the day. In many of these patients, fasting or random (post meal but exact post meal hour not known) glucose

$\begin{array}{ccc}\text { May 2011 } & \text { Fasting } & \text { 2hPP } \\ \text { Glucose (mg/dL) } & 121 & 173 \\ \text { HbA }_{1} \mathrm{c}(\%) & 8.4 & \\ \text { Average glucose (mg/dL) } & 194 & \\ \text { BUN (mg/dL) } & 44 & 49 \\ \text { Serum creatinine (mg/dL) } & 1.56 & 1.64 \\ \text { eGFR (ml/min) } & 34 & 32\end{array}$

ranges between 200 and $300 \mathrm{mg} / \mathrm{dL}$ (11.1 and 16.6 $\mathrm{mmol} / \mathrm{L}$ ). Author makes no change in their therapy at the first visit. However, if a patient at a first or subsequent office visit reveals random or 2-hour postprandial glucose over $300 \mathrm{mg} / \mathrm{dL}$ (16.6 mmol/L) and decreased kidney function, author urges hospital admission to bring glucose level to less than $200 \mathrm{mg} / \mathrm{dL}(11.1 \mathrm{mmol} / \mathrm{L})$ and to create a regimen to keep the sugar level at that range. The main objective of doing that is to protect kidney function from further deterioration and reduce the risk of entering into dialysis. Here is an example of how postprandial hyperglycemia promptly reduces renal function. This is already published by the author [14].

An 86 y white male was admitted to the hospital for foot ulcer. He had a long history of diabetes and chronic kidney disease, Stage 3. Laboratory results obtained in the first week of July 2011 follow:

Regimen 2. Patients not exposed to insulin therapy, have been treated with multiple oral antidiabetic agents, but find glucose levels going very high. The latter scares them and increases their interest to start on insulin. Before author recommends or starts on insulin therapy, he explains the risks and benefits of insulin therapy. The risks are minimal and mainly slight pain from injections, scarring, and discoloration of the skin from repeated injections. These skin changes are mostly cosmetic but pose no threat to life. Skin infection from insulin injecttion is rare, if the same syringe with needle is not used more than once and skin is cleaned with alcohol swab before injection. Skin infection, such as furuncles and carbuncles, are common only in those with uncontrolled diabetes and living in unhygienic conditions, as in underdeveloped countries. Author observed huge carbon- 
cles in patients with uncontrolled diabetes in Fiji Island.

$\begin{array}{ccc}\text { July 2011 } & \text { Fasting } & \text { 2hPP } \\ \text { Glucose }(\mathrm{mg} / \mathrm{dL}) & 147 & 213 \\ \text { BUN }(\mathrm{mg} / \mathrm{dL}) & 16 & 16 \\ \text { Serum creatinine }(\mathrm{mg} / \mathrm{dL}) & 1.92 & 2.10 \\ \text { eGFR }(\mathrm{ml} / \mathrm{min}) & 35 & 32 \\ \mathrm{HbA}_{1} \mathrm{c}(\%) & 9 & \\ \text { Average glucose }(\mathrm{mg} / \mathrm{dL}) & 212 & \end{array}$

Note: with elevation of $2 \mathrm{hPP}$ glucose, serum creatinine was increased accompanied by a decrease of eGFR. BUN did not change. Author did not find any correlation between glycemic level and BUN level [14].

Slight weight gain is a common place with insulin therapy but is not a concern for active individuals. Notwithstanding these minor risks, the benefits of insulin therapy are overwhelming; mainly by achieving satisfactory glycemic control which provides insurance against the horrible complications of uncontrolled diabetes namely foot ulcer, gangrene, and amputation, progressive kidney failure, erectile dysfunction, and heart attack.

\section{INITIATION AND SCHEDULE OF INSULIN}

1) Here is how author initiates insulin therapy. He starts with 20 units of Lantus insulin, after breakfast and dinner at 12 hours apart. This dosage is increased at an interval of 4 to 5 weeks until satisfactory glucose control is achieved. Most or almost all patients need additionally regular insulin according to sliding scale. Author prescribes Novolin $\mathrm{R}$ as per standard sliding scale:

$\begin{array}{ccc}\text { Fingerstick Glucose Level } & \text { Novolin R } \\ \mathrm{mg} / \mathrm{dL} & \mathrm{mmol} / \mathrm{L} & \text { in units } \\ 150-200 & 8.3-11.1 & 4 \\ 201-250 & 11.1-13.8 & 8 \\ 251-300 & 13.8-16.6 & 12 \\ 301-350 & 16.7-19.4 & 16 \\ 351-400 & 19.5-22.2 & 20\end{array}$

Above 400, author advises that patient's call his/her own primary doctor, author himself or go to the emergency room of a nearby hospital to determine the cause of uncontrolled hyperglycemia.

Different prescribers prescribe different schedule of short acting insulin to control post-meal surge. A common practice is to prescribe a rapid-acting insulin, such as insulin aspart (NovoLog®) or insulin Lispro (Huma$\log () 10$ units just before meal or with meal. The problem with this type of prescription is the insulin effect before post-meal surge, leading to hypoglycemia. On the other hand, the author recommends taking regular insulin on a sliding scale 1 - 2 hours after meal. In this way, glucose will remain at less than $200 \mathrm{mg} / \mathrm{dL}(<11.1 \mathrm{mmol} /$ $\mathrm{L}$ ) in most of the time. Fundamentally, there is no difference between regular insulin and rapid-acting insulin. Long time ago, a study from United Kingdom showed that glycemic control was equally tight during treatment with human regular insulin (HbA1c, 6.2\% $\pm 0.8 \%$ ) and insulin Lispro $(6.0 \% \pm 0.9 \%)$ [17].

Uncontrolled hyperglycemia is most commonly due to lack of adherence to a diabetic diet intentionally or otherwise. However, even in best of circumstances, uncontrolled hyperglycemia could be due to urinary tract infection, flu, or pneumonia, in and of itself, as well as a result of failure to take prescribed doses of insulin due to the illness. Treatment of these incidental conditions along with aggressive insulin therapy help to restore good glycemic control.

2) As patients become comfortable with insulin therapy, oral antidiabetic drugs are gradually discontinued, one in each visit after the first visit. For example, if a patient was taking three different oral antidiabetic agents, all three will be discontinued in three separate consecutive office visits at an interval of six to eight weeks. All author's patients are treated solely with a combination of long acting and short acting insulins as stated above.

3) Frequent office visits to maintain glucose and blood pressure controls

Typically, author follows his patients every four to five weeks in the office in order to ascertain glycemic control, blood pressure (BP) control and renal function control. Author's focus is renal function which serves as the mirror of how well they are managing glycemic and BP controls. It is evident if BP remains high $(>140 / 90 \mathrm{~mm}$ $\mathrm{Hg}$ ) renal function deteriorates despite good glycemic control. Author's goal is to keep renal function stable at the level they were first seen, or improve but definitely not get worse. How this is accomplished will be shown later. Visits are lengthened up to eight to ten weeks apart when all the above controls are stable.

\subsection{MONITORING OF GLYCEMIC (GLUCOSE) CONTROL}

There are many ways to monitor day-to-day glucose control. Finger stick glucose levels by the patients themselves are by far the best. Traditionally, most patients have done or still do sugar testing at fasting and before each meal. Author recommends checking 1 to 2 hours after each meal, at bedtime, and upon wake up in the middle of night. The most important glucose level to watch is the post-meal surges. These post-meal surges can cause profound vascular damage. Glucose levels run like peaks and valleys. Lantus twice daily may maintain the valleys. Peaks need to be encumbered by regular insulin, such as Novolin R. Although it is generally considered that peaks are harmful, no study was ever done to determine if the valleys are harmless. Author recommends patients to record all glucose readings and bring to office during scheduled visits. He reviews with the patients' number of readings less than $200 \mathrm{mg} / \mathrm{dL}(<11.1 \mathrm{mmol} / \mathrm{L})$ and more than $200 \mathrm{mg} / \mathrm{dL}(>11.1 \mathrm{mmol} / \mathrm{L})$ and compar- 
es those levels with laboratory reports of fasting and 2hour postprandial glucose levels, $\mathrm{HbAlc}$, and average glucose levels. We found $\mathrm{HbA} 1 \mathrm{c}$ and average glucose levels are synonymous. It is a tedious job both for the patients and the doctors to keep up with the monitoring of glucose control. The tediousness of glucose monitoring compel patients and the doctors to resort to alternative method of glycemic control via oral antidiabetic agents with or without the full knowledge that oral antidiabetic agents lower fasting glucose levels as much as insulin, but not 2hPP glucose levels.

\subsection{Early Morning Glycemic Surge}

Early morning glycemic surge giving rise to fasting hyperglycemia is not uncommon even in the most compliant patients. This fasting hyperglycemia is a part of early morning hormonal surge, such as high cortisol or epinephrine and noreprinephrine level. In hypertensive patients, blood pressure peaks are common in early morning hours. Therefore, it is prudent to state that these hormones surge increase blood pressure as well as blood glucose levels. Epinephrine causes glycogenolysis by converting liver glycogen into glucose. These hormones also inhibit uptake of glucose by the liver. Apparently, liver plays an important role in fasting and postprandial hyperglycemia. However, the pathways of the interactive role of liver in sustaining hyperglycemia are not yet elucidated. Author feels that until we know more about liver's role in early morning glycemic surge, it is appropriate to use an extra dose of 10 units of Lantus or 5 to 6 units of Novolin $\mathrm{R}$ at bedtime, which may mitigate early morning hyperglycemic surge.

Interestingly, this early morning hyperglycemic surge is conducive to good sleep; whereas, taking an extra dose of insulin at bedtime may increase the risk of hypoglycemic reactions. One of the hypoglycemic reactions is waking up in the early morning with perspiration or with an urge to go to bathroom. Perhaps the severity of hypoglycemic reactions may be reduced with fine adjustment of bedtime insulin over a period of time and consuming 6 to 8 ounces of juice or milk before going to bed.

\subsection{BP CONTROL}

Typically, author prescribes the following drugs for BP control: a beta blocker (BB), atenolol (Tenormin $\AA$ ) or metoprolol (Lopresssor®) $50 \mathrm{mg}$ P.O. daily, singly; a second generation dihydropyridine calcium channel blocker (CCB), amlodipine (Norvasc $\AA$ ) 5 to $10 \mathrm{mg}$ P.O. once or twice daily, or isradipine (Dynacirc $\AA$ ) 5 to $10 \mathrm{mg}$ P.O. once or twice daily or a combination of two to keep BP $<140 / 80 \mathrm{mmHg}$. If the patient was already taking nondihydropyridine $\mathrm{CCB}$ such as Verapamil or diltiazem and $\mathrm{BP}$ is under control, no change is made. If BP is not under control with a combination of $\mathrm{BB}$ and $\mathrm{CCB}$, either central inhibitor alphamethyldopa (Aldomet ${ }^{\circledR} 250$ to $500 \mathrm{mg}$ P.O. TID or hydrochlorothiazide (HCTZ) 12.5 to $25 \mathrm{mg}$ P.O. once or twice daily is prescribed. BP control rarely poses a problem. Most importantly, author doesn't prescribe angiotensin converting enzyme inhibitor (AC$\mathrm{EI})$ or angiotensin receptor blocker (ARB) to any patient. The reason is that this group of drugs, almost invariably, will cause recurrent acute renal failure or slow deterioration of renal function to end stage renal failure. Use of ACEI / ARB has been the most important reason for many diabetes patients entering into dialysis. This scenario has been substantiated first by the author as early as 1992 and published in 1994 [18] and subsequently thereafter $[19,20]$.

However, there are a few diabetes patients who progress into end stage renal failure. They are typically noncompliant, do not follow diet therapy and are inconsistent in taking the insulin. Their glucose levels vary all the time between $300-500 \mathrm{mg} / \mathrm{dL}$. They are aware of the danger of these glucose levels but apparently don't care enough to follow the regimen and instruction provided. They also develop heavy proteinuria or nephrotic syndrome which has a serious impact on renal function.

a) Oral Hypoglycemic Agents

Oral hypoglycemic agents, such as biguanide, metformin $500 \mathrm{mg}$ twice daily, increasing to $1000 \mathrm{mg}$ twice daily or sulfonylurea, glyburide $5 \mathrm{mg}$ twice daily, increasing to $10 \mathrm{mg}$ twice daily, in addition to diet control and weight reduction can be recommended in those with 2hPP glucose level consistently less than $200 \mathrm{mg} / \mathrm{dL}$ (< $11.1 \mathrm{mmol} / \mathrm{L}$ ). Oral hypoglycemic agents are unsafe in those with acute or chronic renal failure because of irreversible hypoglycemia. Metabolic acidosis of variable severity is another complication of metformin. Metabolic acidosis can be a serious threat in those with impaired renal function.

b) Acarbose

The only oral antidiabetic agent author recommends is acarbose. He recommends acarbose in combination with insulin in obese and diet noncompliant patients. Acarbose is an alpha-glucosidase inhibitor, which competitively inhibits the alpha-glucosidase enzymes in the gut that digests dietary starch and sucrose. Two of these drugs acarbose and miglitol are available for clinical use. Both drugs delay the absorption of carbohydrate and lower postprandial glycemic surges. Acarbose is available as 50 $\mathrm{mg}$ and $100 \mathrm{mg}$ tablets. Author starts as $50 \mathrm{mg}$ with breakfast, lunch, and dinner but increases to $100 \mathrm{mg}$ with lunch and dinner to minimize postprandial hyperglycemic surge. The common side effect of these drugs is flatulence. This is caused by undigested carbohydrate reaching the lower bowel, where gases are produced by bacterial flora. In small number of patients, troublesome diarrhea develops, requiring discontinuation of the drug. 
A slight increase in liver enzymes may be observed, requiring dosage reduction or discontinuation of the drug.

c) Diet Alone

Diet control alone works in achieving glycemic control. Here is a 60 year white female weighing $237 \mathrm{lbs}$. was seen in consultation in author's office in November of, 2009 , for decreased kidney function. She has a history of diabetes and hypertension for 10 years. She was treated with accupril (ACEI) $40 \mathrm{mg}$ tablet daily, hydrochlorothiazide $25 \mathrm{mg}$ daily (which always increases glucose level mimicking diabetes), Lipitor $40 \mathrm{mg}$ daily for hyperlipidemia, and fluoxetine $20 \mathrm{mg}$ daily for depression. She didn't have any laboratory done except the information that her kidney function was decreased. A glomerular filtration rate of $46 \mathrm{ml} / \mathrm{min}$ (normal $>60 \mathrm{ml} / \mathrm{min}$ ) was reported. Author discontinued accupril, and hydrochlorothiazide. He prescribed methyldopa to control hypertension. She returned in December of, 2009. Her fasting glucose was $168 \mathrm{mg} / \mathrm{dL}$ (9.3 mmol/L). Average glucose was 209 $\mathrm{mg} / \mathrm{dL}(11.6 \mathrm{mmol} / \mathrm{L})$ and HbA1c 8.9 percent. She didn't receive any antidiabetic therapy. She follows diet therapy. She also has left breast cancer and is treated with chemotherapy and irradiation. Author instructed her to check glucose level 1 to 2 hours post meal. She returned in March of, 2010, and brought her readings. All post meal readings were less than $200 \mathrm{mg} / \mathrm{dL}(<11.1 \mathrm{mmol} / \mathrm{L})$ except one when she ate pie and glucose went up to 214 $\mathrm{mg} / \mathrm{dL}(11.8 \mathrm{mmol} / \mathrm{L})$. Her kidney function improved to almost normal level eGFR $57 \mathrm{ml} / \mathrm{min}$ (normal > 60 $\mathrm{ml} / \mathrm{min}$ ). At best, this patient is prediabetic, but drugs like hydrochlorothiazide can tip off the glycemic control and can cause established diabetes. Author prescribed acarbose $50 \mathrm{mg}$ to take with each meal to supplement diet control and weight reduction.

d) Hypoglycemia

Normal laboratory range of glucose is $70-99 \mathrm{mg} / \mathrm{dL}$ (3.8-5.5 mmol/L). Blood glucose of $10-20 \mathrm{mg} / \mathrm{dL}(0.5-$ $1.0 \mathrm{mmol} / \mathrm{L}$ ) below the lower range of normal may produce hypoglycemic symptoms. All insulins, including longacting insulins, can cause hypoglycemia. Hypoglycemic reactions are more common with short-acting or ultrashort-acting insulins than with long-acting insulins. Lantus insulin is least likely to cause hypoglycemic symptoms. Oral hypoglycemic agents can cause protracted

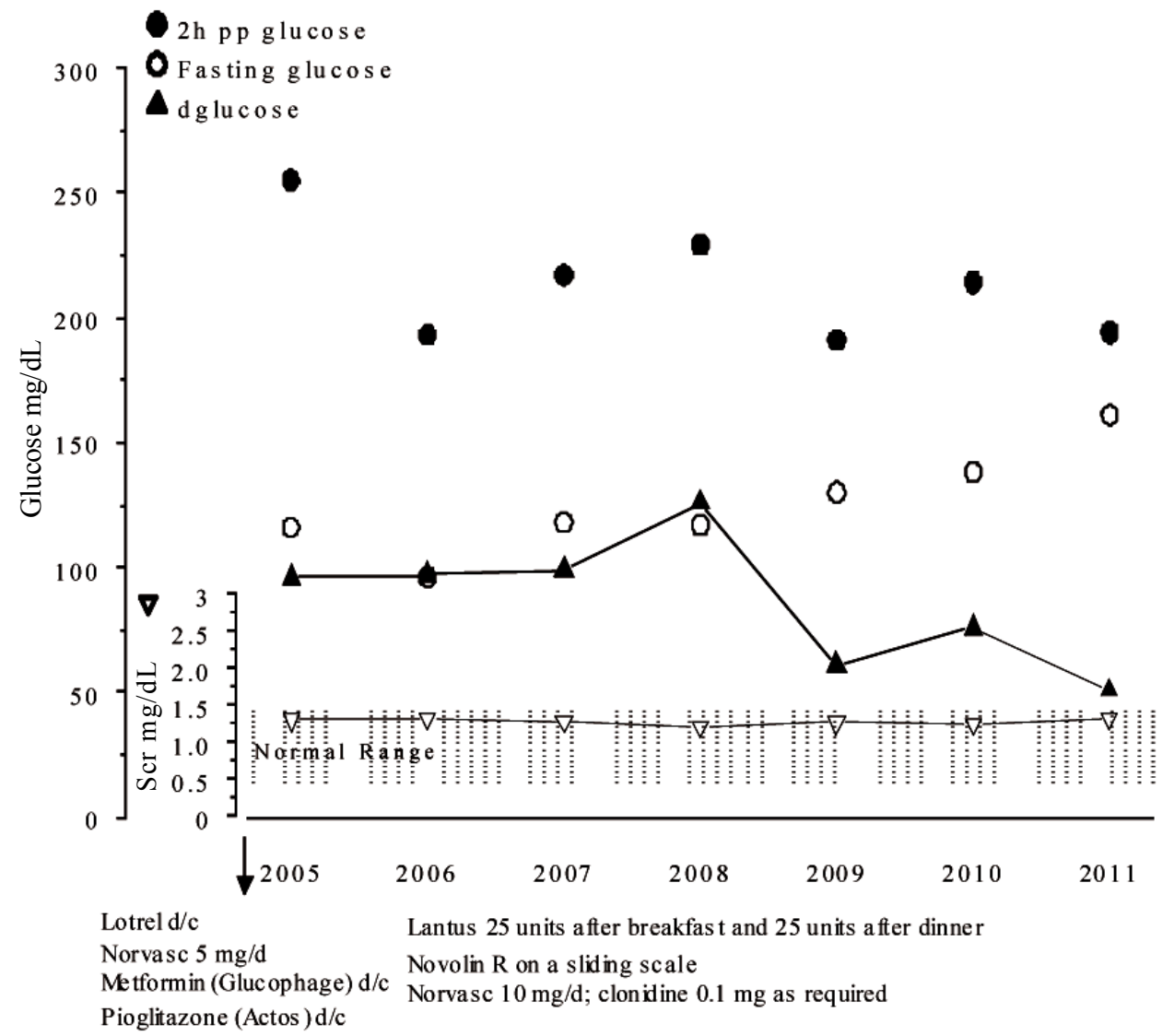

$\mathrm{Scr}=$ Serum creatinine, $\mathrm{d} / \mathrm{c}=$ discontinued; Norvasc (amlodipine) $=$ a second generation dihydropyridine calcium channel blocker, Lotrel $=$ combination of benazepril and amlodipine.

Figure 2. NK 71 AAF history of diabetes $20+$ years total of 28 visits in 7 yrs (average 4 visits/year) average of multiple readings. 
hypoglycemia, particularly in elderly patients and in those with impaired kidney or liver function. It has been shown that glyburide appears to cause a higher incidence of hypoglycemia than chlorpropamide, glipizide, or glimepiride. Most commonly, blood glucose decreases fast and to a very low level when a meal is missed and patients have taken insulin and immediately engaged in a physical activity.

The earliest symptoms of hypoglycemia are blurring of vision with inability to read small letters, unsteadiness or feeling weak in standing or walking, feeling loss of balance, or waking up from sleep drenched in sweat. Difficulty in falling into sleep, feeling nervousness, and feeling excessively hungry are other common symptoms.

a. Relief of hypoglycemic symptoms. The fastest way to obtain relief is to drink 8 ounces of orange juice with one or two pieces of bread or cookies. The solid food holds orange juice for its steady absorption. Effect of orange juice alone is good, but it is better with a solid food. Concomitantly with the above, it is imperative not to engage in physical activity for 15 minutes. Eight ounces $(200 \mathrm{ml})$ orange juice contains 20 grams of sugar. Each gram of sugar in the juice may increase blood sugar by $5 \mathrm{mg} / \mathrm{dL}$ $(0.2 \mathrm{mmol} / \mathrm{L})$. Apple juice or pineapple juice of same volume is also effective, but relief of symptoms with orange juice is faster than other juices. Eight ounces of milk with peanut butter sandwich is also effective. Patients with diabetes will learn over the years by trial and error which of the foods will relieve their symptoms most and in a fastest way. One hour after hypoglycemic episode, finger stick glucose level may be $\geq 200 \mathrm{mg} / \mathrm{dL}$ $(\geq 11.1 \mathrm{mmol} / \mathrm{L})$. Therefore, it is time again to take a low dose of regular insulin to prevent glucose levels rising. It is important that diabetic patients carry juices, cookies, crackers at all times while driving or traveling in a bus, train, or airplane and carry a tag as diabetic in case serious symptoms develop and require emergency attention, such as intravenous infusion of 50 percent dextrose solution to promptly increase blood sugar to near normal to normal level (70 - $99 \mathrm{mg} / \mathrm{dL})$.

Author's paradigm of therapy is best represented in Figure 2. This patient has been followed in author's office for 7 years. Her $2 \mathrm{hPP}$ glucose levels are variable but remain mostly between 200 and $250 \mathrm{mg} / \mathrm{dL}(11.1-13.8$ $\mathrm{mmol} / \mathrm{L}$ ). Most importantly, dglucose is $<100 \mathrm{mg} / \mathrm{dL}(<$ $5.5 \mathrm{mmol} / \mathrm{L}$ ) which is a determinant of preservation of renal function [14]. Her serum creatinine has remained within normal range for the 7 year period.

Finally, in summary a question may be asked; has author's paradigm undergone randomized control trial to determine its effectiveness against other therapies for diabetes? Author does not feel it ethical to compare therapies in diabetes with decreased kidney function or other complication in many of them. Author's goal is to educate the patients to learn to cope with illness, follow the prescribed therapy and not develop progressive renal failure leading to dialysis. Similar comments about clinical trials on diabetes therapy have been made by other authors [21]. Most importantly, diabetes care should be individualized and done in an objective fashion, only to reduce the risk of complications. Arguments about evidence-based medicine depending on the results of clinical trials will simply delay effective treatment and increase the risk of developing complications. Once again, the goal of diabetes therapy is vigilant care by the professsionals to maintain control of postprandial hyperglycemia with insulin therapy which is fundamental to preservation of renal function [14].

\section{REFERENCES}

[1] Brownlee, M. (2005) Pathobiology of diabetic complications: A unifying mechanism. Diabetes; 54, 1615-1625. doi:10.2337/diabetes.54.6.1615

[2] Giugliano, D., Ceriello, A. and Paolisso, G. (1996) Oxidative stress and diabetic vascular complications. Diabetes Care; 19, 257-267. doi:10.2337/diacare.19.3.257

[3] Mandal, A.K., Ping, T., Caldwell, S.J., Bagnell, R. and Hiebert, L.M. (2006)Electron microscopic analysis of glucose-induced endothelial damage in primary cell culture: possible mechanism and prevention. Histology and Histopathology, 21, 941-950.

[4] Hiebert, L.M. and Liu, J. (1990) Heparin protects cultured arterial endothelial cells from damage by toxic oxygen metabolites. Atherosclerosis, 83, 47-51. doi:10.1016/0021-9150(90)90129-7

[5] Yokokawa, K., Mandal, A.K., Kohno, M., Horio, T., Murakawa, K., Yasunari, K. and Takeda, T (1992) Heparin suppresses endothelin-1 action and production in spontaneously hypertensive rat. American Journal of Physiology, 263, R1035-R1041.

[6] Mandal, A.K., Puchalski, J.T., Lemley-Gillespie, S., Taylor, C.A. and Kohno, M. (2000) Effect of insulin and heparin on glucose-induced vascular damage in cell culture. Kidney International, 57, 2492-2501. doi:10.1046/j.1523-1755.2000.00108.x

[7] Ohkubo, Y., Kishikawa, H., Araki, E., Miyata, T., Isami, S., Motoyoshi, S., et al. (1995) Intensive insulin therapy prevents the progression of diabetic microvascular complications in Japanese patients with non-insulin-dependent diabetes mellitus: A randomized prospective 6-year study. Diabetes Research and Clinical Practice, 28, 103117. doi:10.1016/0168-8227(95)01064-K

[8] Reichard, P., Nilsson, R.Y. and Rosenqvist, U. (1993) The effect of long-term insulin treatment on the development of microvascular complications of diabetes mellitus. The New England Journal of Medicine, 329, 304309. doi:10.1056/NEJM199307293290502

[9] The Diabetes Control and Complications Trial Research Group (1993) The effect of intensive treatment of diabetes on the development and progression of long-term complications in insulin dependent diabetes mellitus. The 
New England Journal of Medicine, 329, 977-986. doi:10.1056/NEJM199309303291401

[10] Fabre, J., Balant, L.P., Dayer, P.G., Fox, H.M. and Vernet, A.T. (1982) The kidney in maturity onset diabetes mellitus: a clinical study of 510 patients. Kidney International, 21, 730-738. doi:10.1038/ki.1982.90

[11] Kooy, A., de Jager, J., Lehert, P., Bets, D., Wulffelé, M.G., Donker, A.J.M. and Stehouwer, C.D.A. (2009) Longterm effects of metformin on metabolism and microvascular and macrovascular disease in patients with Type 2 diabetes mellitus. Archives of Internal Medicine, 169, 616-625. doi:10.1001/archinternmed.2009.20

[12] Nosadini, R. and Tonolo, G. (2004) Relationship between blood glucose control, pathogenesis and progression of diabetic nephropathy. Journal of the American Society of Nephrology, 15, S1-S5. doi:10.1097/01.ASN.0000093372.84929.BA

[13] Nathan, D.M., Kuenen, J., Borg, R., Zhengtt, Schoenfeld, D. and Heive, R.J.(2008) Translatingthe $\mathrm{A}_{1} \mathrm{C}$ assay into estimated average glucose values. Diabetes Care, 31, 1473-1478. doi:10.2337/dc08-0545

[14] Mandal, A.K., Hiebert, L.M. and Khamis, H. (2011) dGlucose is linked to renal function changes in diabetes. Diabetes Research and Clinical Practice, 91, 190-194. doi:10.1016/j.diabres.2010.11.013

[15] Palumbo, P.J. (2004) The case for insulin treatment early in type 2 diabetes. Cleveland Clinic Journal of Medicine, 71, 385-405. doi:10.3949/ccjm.71.5.385

[16] Holman, R.R., Paul, S.K., Bethel, M.A., Mathews, D.R. and Neil, H.A. (2008) 10 year follow up of intensive glucose control in type 2 diabetes. New England Journal of Medicine, 359, 1577-1589. doi:10.1056/NEJMoa0806470

[17] Heller, S.R., Amiel, S.A., Mansell, P., UK Lispro Study Group (1999) Effect of the fast-acting insulin analog Lispro on the risk of nocturnal hypoglycemia during intensified insulin therapy. Diabetes Care, 22, 1607-1611. doi:10.2337/diacare.22.10.1607

[18] Mandal, A.K., Markert, R.J., Saklayen, M.G., Mankus, R.A. and Yokokawa, K. (1994) Diuretics potentiate angiotensin converting enzyme inhibitor-induced acute renal failure, Clinical Nephrology, 42, 170-174.

[19] Mandal, A.K. and Hiebert, L.M. (2008) Renal protection in diabetes: Is it affected by glucose control or inhibition of renin-angiotensin pathway. Clinical Nephrology, 69, 169-178.

[20] Mandal, A.K. (2010) A reversible of acute renal failure associated with renin-angiotensin inhibitor drugs. International Urology and Nephrology, 2, 567-579.

[21] Hamaty, M. (2011) Insulin treatment for type 2 diabetes: when to start and which to use. Cleveland Clinic Journal of Medicine, 78, 332-342. doi:10.3949/ccjm.78a.10051 